\title{
Poly(methyl acrylate-co-methyl methacrylate)/ montmorillonite nanocomposites fabricated by soap-free emulsion polymerization
}

\author{
Chia-Hsin Lee • An-Ting Chien • Ming-Huei Yen • \\ King-Fu Lin
}

Received: 22 September 2007 / Accepted: 14 January 2008/Published online: 7 February 2008

(C) Springer Science + Business Media B.V. 2008

\begin{abstract}
The exfoliated poly(methyl acrylate-co-methyl methacrylate)/montmorillonite (MMT) nanocomposite latex solutions fabricated by soap-free emulsion polymerization were able to cast into a film. The films were transparent and ductile unless more than $5 \mathrm{wt} \%$ of MMT was incorporated. With the MMT content higher than $5 \mathrm{wt} \%$, the inflammable residuals of nanocomposites after combustion could preserve their original film profile acting like an inflammable scaffold. Moreover, as $20 \mathrm{wt} \%$ MMT was incorporated, the yield strength of the films was increased up to 20 times and Young's modulus up to 2,000 times. However, the water vapor permeability coefficient of the films was only decreased down to its half value. This unexpected behavior of permeability was associated with the decrease of $T_{\mathrm{g}}$ as the content of MMT was increased, owing to the large difference of the reactivity ratios between methyl acrylate and methyl methacrylate monomers and their differential absorption to the MMT during copolymerization.
\end{abstract}

Keywords Nanocomposites - Montmorillonite · Poly(methyl acrylate) $\cdot$ Poly (methyl methacrylate) . Emulsion polymerization

C.-H. Lee $\cdot$ M.-H. Yen $\cdot$ K.-F. Lin $(\varangle)$

Department of Materials Science and Engineering,

National Taiwan University,

Taipei, Taiwan, Republic of China

e-mail: kflin@ntu.edu.tw

A.-T. Chien · K.-F. Lin

Institute of Polymer Science and Engineering,

National Taiwan University,

Taipei, Taiwan, Republic of China

\section{Introduction}

Exfoliated polymer/montmorillonite (MMT) nanocomposites have been widely investigated in recent years owing to their superior properties compared to the conventional composite materials [1-5]. Montmorillonite (MMT) is a natural clay, which is constructed of repeating triple-layer nanoplatelets composed of two tetrahedral silica layers fused into an edge-shared octahedral layer of alumina with a thickness of $\sim 1 \mathrm{~nm}$ and a length of several hundred nanometers [6]. Stacking of the nanoplatelets creates a gap between the nanoplatelets called the interlayer or gallery. Isomorphic substitution within the layers, such as $\mathrm{Si}^{+4}$ by $\mathrm{Al}^{+3}$ or $\mathrm{Al}^{+3}$ by $\mathrm{Mg}^{+2}$, generates negative charges that are counterbalanced by some cations, such as $\mathrm{Na}^{+}$in the gallery. Because of the weak interactions between the stacking layers, the cations inside the gallery can be easily exchanged by other cations. The maximum capacity for the cation exchange is known as the cation exchange capacity (CEC), which is expressed as meq/100 g. Thus, the exfoliated MMT nanoplatelets carry positive ions on the surface so that they can be considered as a two-dimensional electrolyte [7]. Researchers usually adopted certain organic modifications for MMT to explore the exfoliated nanocomposites. A few amount of the dispersed MMT in polymeric matrix can significantly improve the mechanical properties [8], thermal stability [9], and barrier properties [10]. Various polymers, processes, and characterizations associated with the polymer/MMT nanocomposites have been reported recently [11-15]. However, the adopted surfactants to organize the MMT are a small molecule that would degrade the thermal stability and durability of the fabricated nanocomposites.

Soap-free emulsion polymerization [16-19] is a clean and prevailing process to manufacture the polymeric latices. 
Recently, we have successfully adopted the soap-free emulsion polymerization to fabricate the exfoliated poly (methyl methacrylate) (PMMA)/MMT nanocomposite latices [20]. During polymerization, the polymerizing chains were aggregated into a disk form inside the clay interlayer regions for micellation and exfoliated the MMT. The exfoliation of MMT was almost completed in the micellation stage. However, because PMMA has a glass transition temperature $\left(T_{\mathrm{g}}\right)$ of $105^{\circ} \mathrm{C}$, the as-formed exfoliated PMMA/MMT nanocomposite latex particles are too rigid to form a film after casting. Therefore, their applications are limited.

In this work, in order to decrease the $T_{\mathrm{g}}$, we fabricated the poly(methyl acrylate-co-methyl methacrylate) (P(MAco-MMA))/MMT nanocomposite latices through soap-free emulsion copolymerization of methyl acrylate (MA) and methyl methacrylate (MMA) monomers in various weight ratios. As the weight ratio of MA to MMA was increased to 3:1 or higher, the fabricated P(MA-co-MMA)/MMT nanocomposite latex solutions could be successfully cast into a film. Thus, the transparency, $T_{\mathrm{g}}$, water vapor permeability and mechanical properties of the films were investigated and the results were associated with the reactivity ratios of monomers and the preferential adsorption of monomers to the MMT interlayer regions during emulsion copolymerization.

\section{Experimental}

\section{Materials}

MA and MMA monomers were purchased from Acros. Both were distilled under reduced pressure for purification before used. Potassium persulfate (KPS) purchased from Acros was used as the initiator without further purification. Montmorillonite (MMT, PK-802), with cationic exchange capacity $(\mathrm{CEC})=114 \mathrm{meq} / 100 \mathrm{~g}$, was obtained from PAIKONG Nano Technology in Taiwan.

Preparation of polymer-clay latex solutions and films

To a two-neck flask that has been loaded with $125 \mathrm{ml}$ deionized water was added $0.3852 \mathrm{~g}$ KPS and an allocated amount of MMT for preparation of P(MA-co-MMA)/MMT nanocomposite latices containing $0,1,5,10$ and $20 \mathrm{wt} \%$ MMT, respectively. The weight ratios between MA and MMA monomers were set to $3 / 1,4 / 1$, and $5 / 1$, respectively for copolymerization. The mixed monomers of $9.5 \mathrm{~g}$ were added to the flask with stirring and then heated to $70^{\circ} \mathrm{C}$ for copolymerization. After $\sim 24 \mathrm{~h}$ until no further polymerization was detected, a few amount of the latex solution was removed for transmission electron microscopic (TEM) observation. The remaining latex solutions after stirring homogeneously were poured into an aluminum foil rectangular mode with dimensions of $15 \times 30 \mathrm{~cm}^{2}$ and then dried at $50^{\circ} \mathrm{C}$ in an oven. After $24 \mathrm{~h}$, the film was formed with a uniform thickness of $\sim 0.2 \mathrm{~mm}$. The P(MA-co-MMA)/MMT nanocomposite containing $1 \mathrm{wt} \%$ MMT was designated as $\mathrm{P}$ (MA-co-MMA)/1\%MMT nanocomposite and so on.

\section{Characterization}

Morphology of the nanocomposite latex was investigated with a JOEL JSM-1230 TEM. X-ray diffraction patterns of the film and powder samples were recorded by using a Philip XRD-500 X-ray diffraction analyzer with nickel-filtered $\mathrm{Cu}$ Ka radiation at $30 \mathrm{kV}$ and $20 \mathrm{~mA}$. Molecular weight of the $\mathrm{P}$ (MA-co-MMA) copolymers and the matrixes removed from their respective nanocomposite latices by Soxhlet extraction were measured by gel permeation chromatography, which was carried out at $40^{\circ} \mathrm{C}$ with a Testhigh series III pump and a Testhigh ultraviolet-visible (UV-vis) detector model 500. One Phenol Gel 550A column and two Phenol Gel MXL columns in series were used with THF as a mobile phase $(0.8 \mathrm{ml} / \mathrm{min})$. The molecular weight and molecular weight distributions were estimated by referring to the polystyrene standard. The transmittance of the films was measured by Jasco model 555 UV-vis spectrophotometer. Glass transition temperature of the films was measured by a differential scanning calorimeter (DSC, TA Instrument model 2920) at a heating rate of $10^{\circ} \mathrm{C} / \mathrm{min}$ under nitrogen atmosphere. Data were taken at the second run. Tensile properties of the films such as yield stress, Young's modulus, and elongation were measured by using a Tian-Siang tensile tester according to ASTM D-638 type IV with a cross-head speed of $1 \mathrm{~mm} / \mathrm{min}$ at $30^{\circ} \mathrm{C}$. At least five specimens were measured for each testing results.

Water vapor permeability of the films was measured by following ASTM E-96. The samples were dried at $80^{\circ} \mathrm{C}$ to a constant weight before testing. In general, $\sim 150 \mathrm{ml}$ deionized water was placed into a cylinder cup. The mouth of the cup was then sealed with a dried film specimen and then the cup was placed in an oven maintaining at $40^{\circ} \mathrm{C}$ and $39 \%$ relative humidity. The periodical weight was recorded until the change of weight with time was linear. The slope of the linear region was used to estimate the water vapor transmission $\delta$, which was defined as the weight loss per unit time and unit area of the film specimen. Then, the permeability coefficient $K_{\mathrm{V}}$ of water vapor was estimated by using the following equation.

$k_{\mathrm{V}}=\frac{\delta d}{P_{\mathrm{s}}\left(1-R_{\mathrm{h}}\right)}$

where $d$ is the thickness of film specimen, $P_{\mathrm{s}}$ is the saturated water vapor pressure at testing temperature, and 
$R_{\mathrm{h}}$ is the relative humidity outside the testing cup expressed as a fraction.

\section{Results and discussion}

Morphology of the P(MA-co-MMA)/MMT nanocomposite latices and films

Typical TEM image of the exfoliated P(MA-co-MMA)/MMT nanocomposite latex is shown in Fig. 1. The polymerizing $\mathrm{P}$ (MA-co-MMA) not only exfoliated MMT but also adhered to the exfoliated MMT nanoplatelets so that no well defined P(MA-co-MMA) matrix was observed. Similar TEM images have also been observed for the exfoliated polyvinyl acetate/ MMT nanocomposite latex prepared by the same method [21]. As the fabricated P(MA-co-MMA)/MMT nanocomposite latices were cast into films, their X-ray diffraction patterns have no diffraction peak contributed by the original interlayer $\mathrm{d}_{001}$-spacing of neat MMT appeared at $2 \theta=\sim 7^{\circ}$ [20] as typically shown in Fig. 2, indicating that MMTs have been fully exfoliated and dispersed in the film. The number average molecular weight and polydispersity index (PDI) of P(MA-co-MMA) copolymers and their matrices removed from the nanocomposite latices prepared by various weight ratios of MA to MMA with various contents of MMT were summarized in Table 1. In general, the molecular weight was not substantially changed as the weight ratio of MA to MMA and the MMT content were changed. All the number average molecular weights were higher than 100,000.

The cast P(MA-co-MMA)/MMT nanocomposite films were transparent even though the films became blurring as the content of MMT exceeded $5 \mathrm{wt} \%$ owing to the light scattering from exfoliated MMT nanoplatelets. Figure 3 shows the typical photographs of the cast films. Their

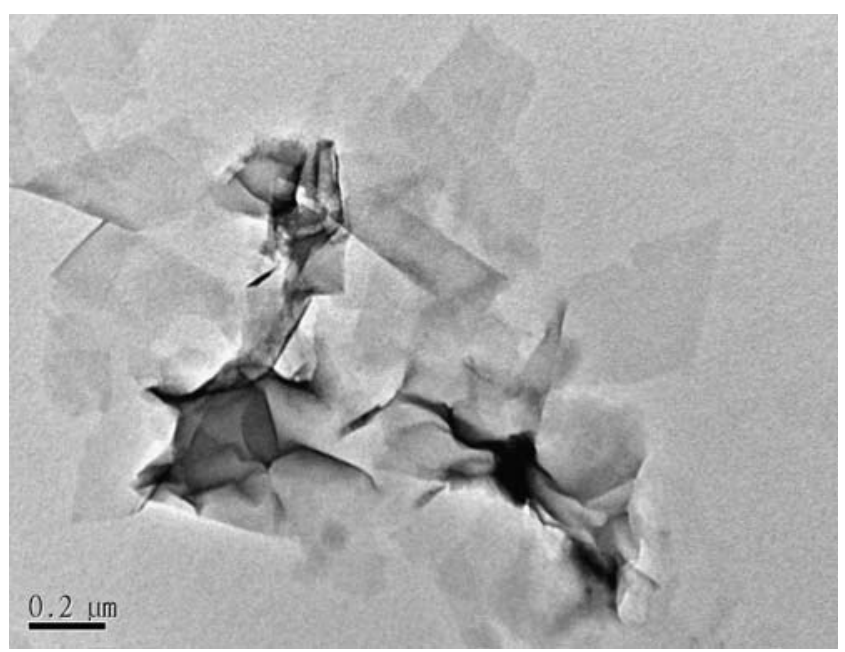

Fig. 1 TEM micrograph of P(MA-co-MMA)/10\%MMT nanocomposite latex prepared by 3:1 weight ratio of MA to MMA

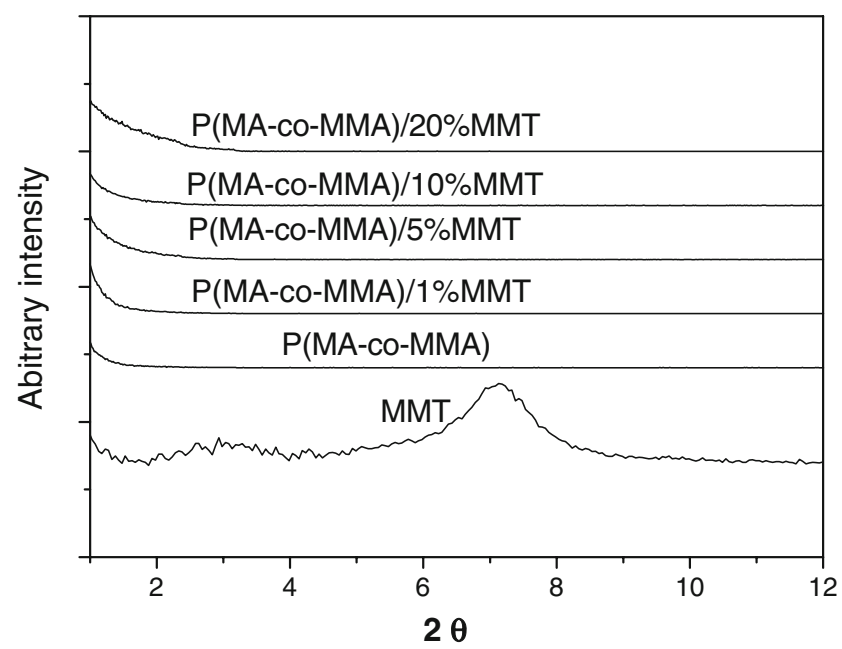

Fig. 2 X-ray diffraction patterns of P(MA-co-MMA)/MMT nanocomposite films with the indicated content of MMT prepared by $3: 1$ weight ratio of MA to MMA. That of the pristine MMT particles was also included for comparison

absolute transmittance measured by the UV-vis spectrophotometer was present in Fig. 4. Because of no absorption peak in the visible region of UV-vis spectra, the P(MA-coMMA)/MMT nanocomposite films are transparent. As all the cast films were subjected to the combustion, the char residuals of $\mathrm{P}(\mathrm{MA}-\mathrm{co}-\mathrm{MMA}) / \mathrm{MMT}$ nanocomposite films with the MMT content higher than $5 \mathrm{wt} \%$ could preserve their original film profile. However, the neat copolymer films were immediately burned into black ashes as soon as they closed to the flame. Apparently, the films containing MMT performed a retarded burning speed. According to our previous study on the morphology of cast PVAc/MMT nanocomposite films prepared from the similar soap-free emulsion polymerization [21], the MMT nanoplatelets were dispersed evenly and flattened almost completely along the film surface. In other words, the exfoliated MMT nanoplatelets acted like a scaffold to preserve the film profile after burned. It is noteworthy that as combustion occurs, this scaffold would have a potential to block the flame transportation.

\section{Properties of the nanocomposite films}

The $T_{\mathrm{g}}$ measured from the DSC thermograms of the P(MAco-MMA)/MMT nanocomposite films prepared by various weight ratios of MA to MMA with various contents of MMT were summarized in Table 2. Notably, $T_{\mathrm{g}}$ of PMMA is $105^{\circ} \mathrm{C}$, whereas that of PMA is $6^{\circ} \mathrm{C}$ [22]. By using the Fox equation [23] to estimate the $T_{\mathrm{g}}$ of $\mathrm{P}$ (MA-co-MMA) copolymers,

$\frac{1}{T_{\mathrm{g}}}=\frac{W_{\mathrm{MA}}}{T_{\mathrm{g}, \mathrm{PMA}}}+\frac{W_{\mathrm{MMA}}}{T_{\mathrm{g}, \mathrm{PMMA}}}$

where $W_{\mathrm{MA}}$ and $W_{\mathrm{MMA}}$ are the weight fractions of MA and MMA in the copolymer, and $T_{\mathrm{g}, \mathrm{MA}}$ and $T_{\mathrm{g}, \mathrm{PMMA}}$ are the $T_{\mathrm{g}}$ 
Table 1 Molecular weight data of P(MA-co-MMA) matrices removed from their MMT nanocomposite latices

\begin{tabular}{lccccc}
\hline P(MA-co-MMA)/MMT latex with & MA/MMA=3:1 $\mathrm{Mn} \times 10^{5}$ PDI & MA/MMA=4:1 Mn× $0^{5}$ PDI & MA/MMA=5:1 Mn×105 PDI \\
\hline $0 \%$ MMT & 2.48 & 1.83 & 2.28 & 2.38 & 2.35 \\
$1 \%$ MMT & 1.09 & 2.50 & 2.23 & 2.50 & 2.22 \\
$5 \%$ MMT & 2.63 & 2.53 & 2.18 & 2.72 & 2.18 \\
$10 \%$ MMT & 2.10 & 1.54 & 2.19 & 2.66 & 2.48 \\
$20 \%$ MMT & 3.53 & 2.74 & 2.23 & 2.71 & 3.27 \\
\hline
\end{tabular}

of PMA and PMMA. The $T_{\mathrm{g}}$ of copolymers with weight ratios of MA to MMA equal to $3: 1,4: 1$ and $5: 1$ will be 25.6 , 21.4 and $18.7^{\circ} \mathrm{C}$, respectively lower than those directly measured by DSC. It should be noted that the reactivity ratio $r_{1}$ of MA in MA/MMA copolymerization is 0.4 , whereas $r_{2}$ of MMA is 2.15 [24]. The type of copolymerization is close to the ideal copolymerization, that is

$\frac{d[\mathrm{MA}]}{d[\mathrm{MMA}]}=\frac{r_{1}[\mathrm{MA}]}{[\mathrm{MMA}]}$

where [MA] and [MMA] are the concentrations of MA and MMA during copolymerization. Accordingly, the MMA monomers should be reacted about twice more than its fraction in the initial copolymerization. Because the conversion was only $\sim 90 \%$, most of the removed unreacted monomers at the final stage of emulsion polymerization should be MA. As a result, the estimated $T_{\mathrm{g}}$ of P(MA-coMMA) is lower than the measured one. Interestingly, as MMT participated in the emulsion copolymerization, the $T_{\mathrm{g}}$ of fabricated $\mathrm{P}(\mathrm{MA}-\mathrm{co}-\mathrm{MMA}) / \mathrm{MMT}$ nanocomposites became close to the theoretical values or even lower (see Table 2). It is contradictory to the general observation that incorporating the exfoliated MMT would increase the $T_{\mathrm{g}}$ of

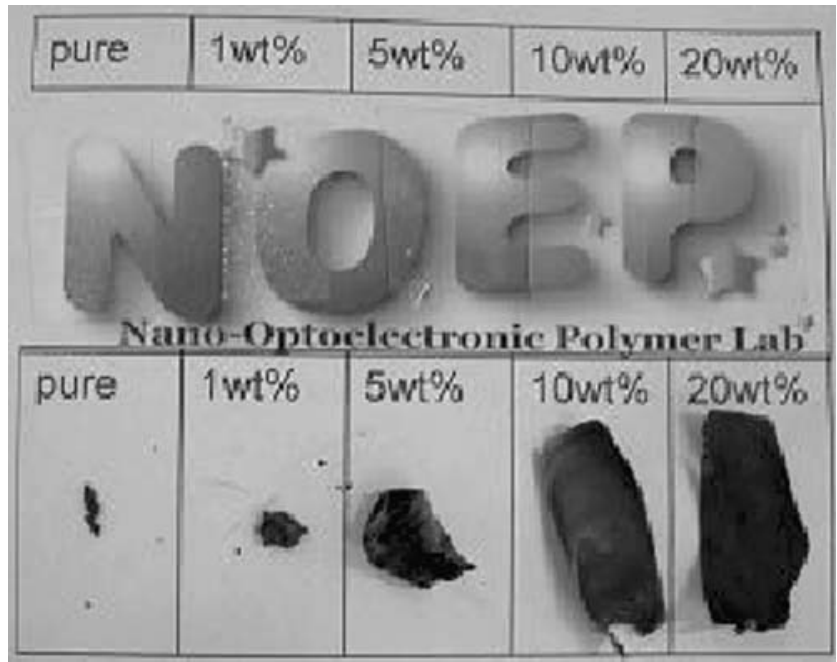

Fig. 3 Photograph of the P(MA-co-MMA)/MMT nanocomposite films prepared by 3:1 weight ratio of MA to MMA with the indicated MMT contents (upper), and their residuals after combustion (lower) polymer matrix [21]. We have observed that micellation usually occurred in the interlayer region of MMT during emulsion polymerization of MMA under the presence of MMT and further polymerization exfoliated MMT [20]. Thus, it is rational to believe that MMT preferred to absorb MA monomer than MMA for copolymerization in micelles, resulting in the lower $T_{\mathrm{g}}$ for the fabricated $\mathrm{P}(\mathrm{MA}-\mathrm{co}-\mathrm{MMA}) /$ MMT nanocomposites compared to the neat copolymers.

The water vapor permeability of fabricated P(MA-coMMA)/MMT nanocomposite films was investigated at $40^{\circ} \mathrm{C}$ following the test method of ASTM E96. The results shown in Fig. 5 indicated that the permeability was decreased with decreasing the weight ratio of MA to MMA and increasing the content of MMT. The temperature of permeability test was higher than the $T_{\mathrm{g}}$ of testing specimens. It is conceivable that permeability is decreased with increasing the $T_{\mathrm{g}}$ of the samples owing to the fact that the free volume was decreased. However, the extent of decreased permeability for P(MA-co-MMA)/MMT nanocomposite films compared to the neat copolymers was not as great as the reported data for the cast PVAc/MMT nanocomposite films [21]. Apparently, it is due to the fact that $T_{\mathrm{g}}$ of the P(MA-co-MMA)/ MMT nanocomposite films is lower than that of neat co-

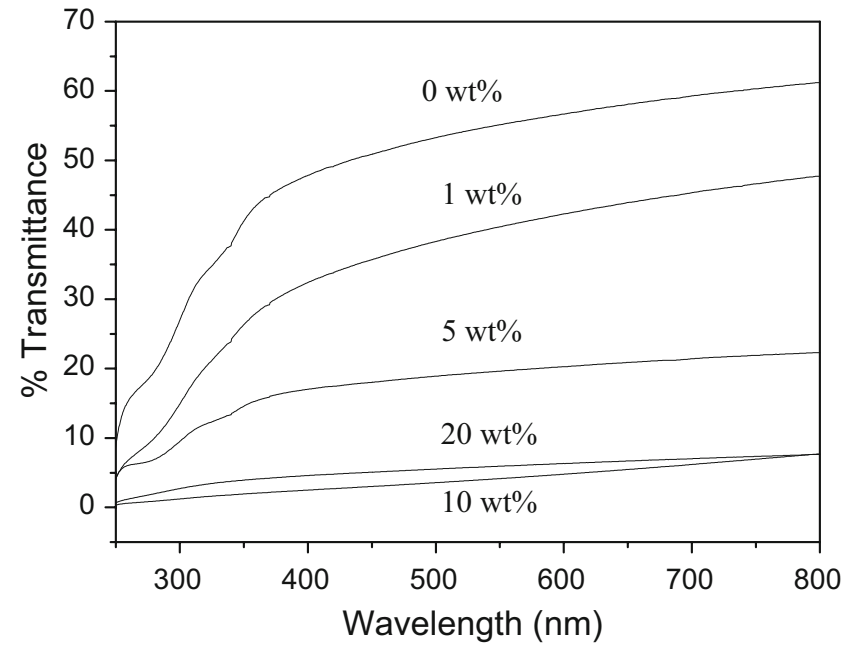

Fig. 4 Transmittance of the P(MA-co-MMA)/MMT nanocomposite films prepared by 3:1 weight ratio of MA to MMA with the indicated MMT contents 
Table 2 Glass transition temperature of P(MA-co-MMA)/MMT nanocomposite films

\begin{tabular}{lccc}
\hline $\begin{array}{l}\text { P(MA-co-MMA)/ } \\
\text { MMT film with }\end{array}$ & $\begin{array}{c}T_{\mathrm{g}},{ }^{\circ} \mathrm{C}(\mathrm{MA} / \\
\mathrm{MMA}=3: 1)\end{array}$ & $\begin{array}{c}T_{\mathrm{g}},{ }^{\circ} \mathrm{C}(\mathrm{MA} / \\
\mathrm{MMA}=4: 1)\end{array}$ & $\begin{array}{c}T_{\mathrm{g}},{ }^{\circ} \mathrm{C}(\mathrm{MA} / \\
\mathrm{MMA}=5: 1)\end{array}$ \\
\hline $0 \%$ MMT & 30 & 33.5 & 27 \\
$1 \%$ MMT & 23 & 18.5 & 18.3 \\
$5 \%$ MMT & 22 & 20 & 17.5 \\
$10 \%$ MMT & 20 & 13.8 & 18.1 \\
$20 \%$ MMT & 18 & 16.8 & 17.9 \\
\hline
\end{tabular}

polymers, creating excess free volume for the water vapor to transport in the polymer matrix.

The tensile properties such as Young's modulus, yield stress and elongation of P(MA-co-MMA)/MMT nanocomposite films prepared by various weight ratios of MA to MMA with various contents of MMT were shown in Fig. 6. It is surprising to find that Young's modulus of the films was decreased as $1 \mathrm{wt} \%$ of MMT was incorporated. Further increase of the MMT content significantly increased the Young's modulus of the films. The Young's modulus could reach up to more than 2,000 times than that of the neat copolymer films as $20 \mathrm{wt} \%$ MMT was incorporated. The decrease of Young's modulus by incorporating $1 \mathrm{wt} \%$ MMT to the copolymers might be due to the decrease of $T_{\mathrm{g}}$, since the $T_{\mathrm{g}}$ of copolymer is close to the testing temperature and that of $\mathrm{P}(\mathrm{MA}-\mathrm{co}-\mathrm{MMA}) / 1 \% \mathrm{MMT}$ nanocomposite films is about $10^{\circ} \mathrm{C}$ lower than the testing temperature(see Table 2). The yield strength of the films was increased with the content of MMT. As the content of MMT was increased to $20 \mathrm{wt} \%$, the yield strength was increased up to 20 times higher than that of the copolymer. As to the elongation, it is surprising to find that for the $\mathrm{P}(\mathrm{MA}-\mathrm{co}-\mathrm{MMA})$ copolymer prepared by the 5:1 weight ratio of MA to MMA, the elongation was increased from 383 to $657 \%$ as $1 \mathrm{wt} \%$

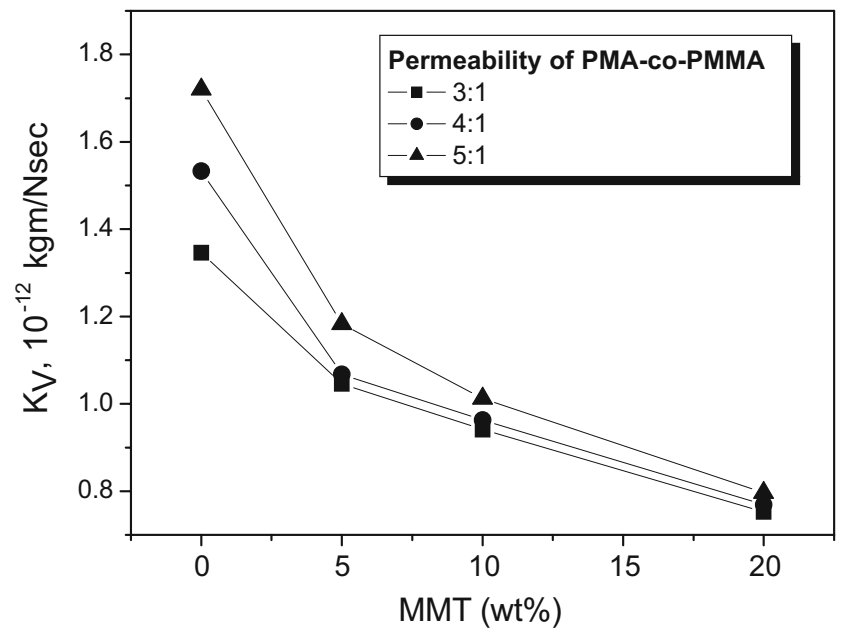

Fig. 5 Permeability coefficient $K_{V}$ of the P(MA-co-MMA)/MMT nanocomposite films as a function of the MMT content, prepared by (square) $3: 1$, (circle) 4:1, and (triangle) 5:1 weight ratio of MA to MMA
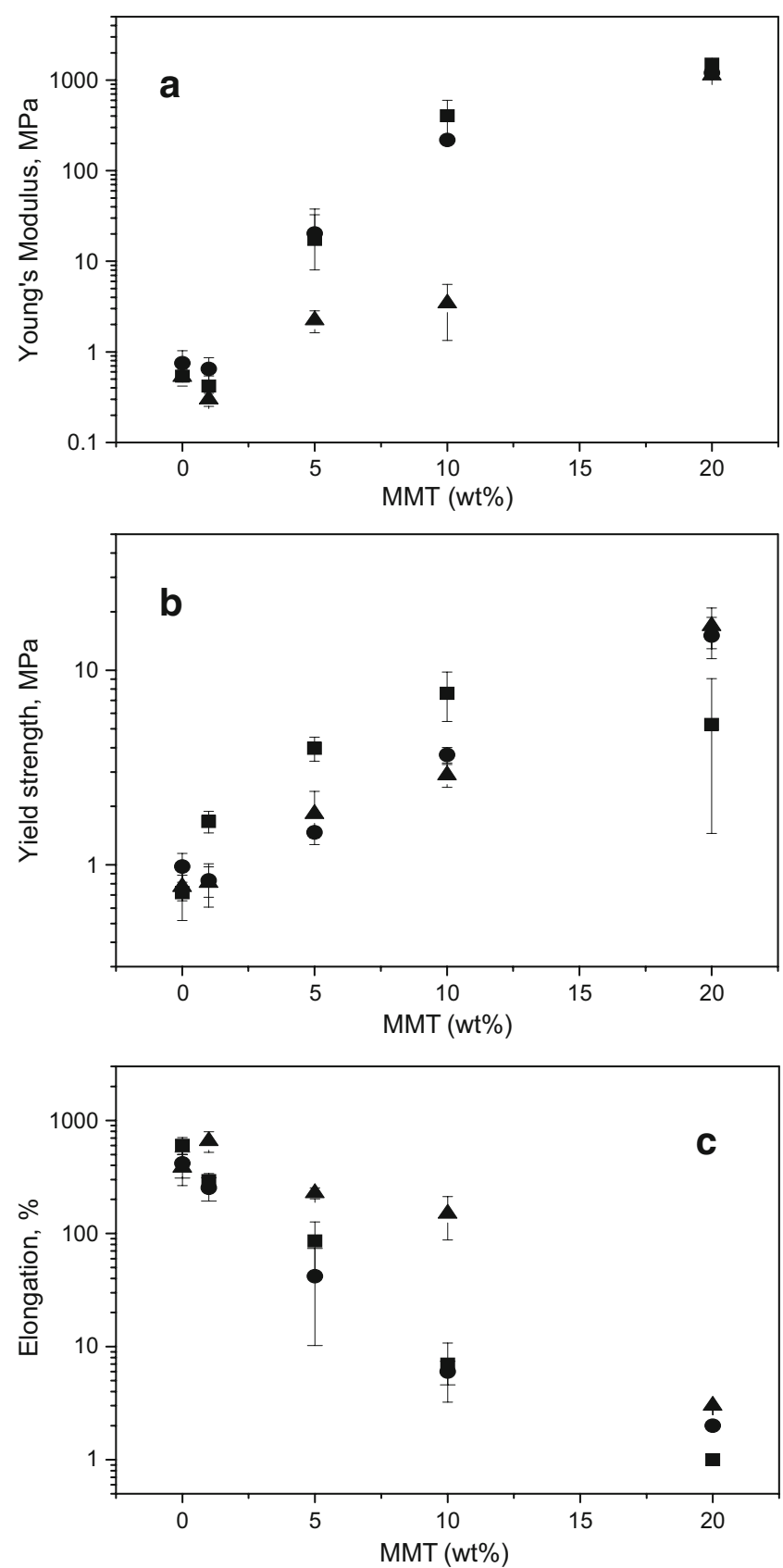

Fig. 6 a Young's modules, b yield stress, and $\mathbf{c}$ elongation of the $\mathrm{P}$ (MA-co-MMA)/MMT nanocomposite films as a function of the MMT content, prepared by (square) 3:1, (circle) 4:1, and (triangle) 5:1 weight ratio of MA to MMA

MMT was incorporated. Further increase of MMT content decreased the elongation. However, the elongation still had $150 \%$ as $10 \mathrm{wt} \%$ MMT was incorporated. Again, in contrast to the $T_{\mathrm{g}}$ of copolymer close to the testing temperature, the $T_{\mathrm{g}}$ of the $\mathrm{P}(\mathrm{MA}-\mathrm{co}-\mathrm{MMA}) / 1 \% \mathrm{MMT}$ nanocomposite films is about $10^{\circ} \mathrm{C}$ lower than the testing temperature so that the specimens became more ductile. Similar ductile behavior for the poly(2-methyoxyethyl acrylate)/MMT nanocomposites with $T_{\mathrm{g}}$ of $-34^{\circ} \mathrm{C}$ was also reported [25]. Notably, for the cast PVAc/1\%MMT nano- 
composite film with $T_{\mathrm{g}}$ slightly higher than the testing temperature, the elongation was significantly retarded by the exfoliated MMT nanoplatelets [21].

\section{Conclusions}

The exfoliated P(MA-co-MMA)/MMT nanocomposite lattices fabricated by soap-free emulsion polymerization were successfully cast into a transparent film. With the MMT content higher than $5 \mathrm{wt} \%$, the inflammable residuals of nanocomposite films after combustion could preserve their original film profile acting like an inflammable scaffold. Owing to the large difference of the reactivity ratios between methyl acrylate and methyl methacrylate monomers and their differential absorption to the MMT during copolymerization, the $T_{\mathrm{g}}$ of $\mathrm{P}(\mathrm{MA}-\mathrm{co}-\mathrm{MMA}) / \mathrm{MMT}$ nanocomposite films was below room temperature and also lower than the $T_{\mathrm{g}}$ of copolymers, leading to more ductile for P(MA-co-MMA)/1\%MMT nanocomposite films compared to neat copolymer. Besides, the water vapor permeability coefficient of the films was only decreased to its half value as $20 \mathrm{wt} \%$ MMT was incorporated. Nevertheless, the yield strength of the films was able to increase up to 20 times and Young's modulus up to 2,000 times as $20 \mathrm{wt} \%$ MMT was incorporated. Based on those superior properties of cast films, the P(MA-co-MMA)/MMT nanocomposite latex solutions should have great potential applications on the coating industries, especially for the fire-retardant coatings.

Acknowledgement The authors acknowledge the financial support of the National Science Council in Taiwan, Republic of China, through Grant NSC95-2216-E-002-206.

\section{References}

1. Pinnavaia TJ, Beall GE (2000) Polymer-clay nanocomposites. Wiley, New York

2. Utracki LA (2004) Clay-containing polymeric nanocomposites. Rapra Technology, Shrewsbury

3. Ke YC, Stroeve P (2005) Polymer-layered silicate and silica nanocomposites. Elsevier, Amsterdam

4. Chuang TH, Guo W, Cheng KC, Chen SW, Wang HT, Yen YY (2004) J Polym Res 11:169

5. Chozhan CK, Alagar M, Sharmila RJ, Gnanasundaram P (2007) J Polym Res 14:319

6. Chen C, Curliss D (2003) Nanotechnology 14:643

7. Tu CW, Liu KY, Chien AT, Yen MH, Weng TH, Ho KC, Lin KF (2008) J Polym Sci A Polym Chem 46:47

8. Tsai TY, Li CH, Chang CH, Cheng WH, Hwang CH, Wu RJ (2005) Adv Mater 17:1796

9. Zhu J, Start P, Mauritz KA, Wilkie CA (2002) Polym Degrad Stabil 77:253

10. Yano K, Usuki A, Okada A (1997) J Polym Sci A Polym Chem 35:2289

11. Fornes TD, Hunter DL, Paul DR (2004) Macromolecules 37:1793

12. Fan XW, Xia CJ, Advincula RC (2005) Langmuir 21:2537

13. Choi YS, Ham HT, Chung IJ (2003) Polymer 44:8147

14. Lin KF, Hsu CY, Huang TS, Chiu WY, Lee YH, Young TH (2005) J Appl Polym Sci 98:2042

15. Zhao Q, Samulski ET (2005) Macromolecules 38:7967

16. Song S, Poehlein GW (1989) J Colloid Interface Sci 128:486

17. Chen YC, Lee CF, Chiu WY (1996) J Appl Polym Sci 61:2235

18. Lin KF, Shieh YD (1998) J Appl Polym Sci 69:2069

19. Lin KF, Shieh YD (1998) J Appl Polym Sci 70:2313

20. Lin KF, Lin SC, Chien AT, Hsieh CC, Yen MH, Lin CS, Chiu WY, Lee YH (2006) J Polym Sci A Polym Chem 44:5572

21. Chien AT, Lin KF (2007) J Polym Sci A Polym Chem 45:5583

22. Tu CW, Liu KY, Chien AT, Lee CH, Ho KC, Lin KF (2008) Eur Polym J DOI 10.1016/j.eurpolymj.2008.01.005

23. Fox TG (1956) Bull Am Phys Soc 1:123

24. Brandrup J, Immergut EH (1989) Polymer handbook, 3rd edn. Wiley-Interscience, New York

25. Haraguchi K, Ebato M, Takehisa T (2006) Adv Mater 18:2250 